\title{
EXPLORANDO A CONSTRUÇÃO DA CARREIRA GERENCIAL: AS RELAÇÕES E INTERAÇÕES ENTRE GERENTES SENIORES E JUNIORES
}

\author{
EXPLORING THE CONSTRUCTION OF MANAGERIAL CAREER: RELATIONSHIPS AND
} INTERACTIONS BETWEEN SENIOR AND JUNIOR MANAGERS

\author{
RAFAELLA CRISTINA CAMPOS ${ }^{1}$ \\ MÔNICA CARVALHO ALVES CAPPELLE ${ }^{2}$ \\ ODEMIR VIEIRA BAETA ${ }^{3}$
}

\begin{abstract}
Resumo: O objetivo deste artigo é explorar aspectos da carreira gerencial no contexto atual de empresas privadas, no ponto de vista de recrutadores seniores de alto escalão hierárquico e juniores recém-contratados. A construção da carreira do indivíduo ganha destaque e passa a ser o foco permanente ao monitorar o status quo e as projeções futuras frente ao posicionamento das organizações que buscam sempre a melhor maneira de reter seus talentos. A pesquisa desenvolvida é qualitativa e a geração de dados se deu por meio de entrevistas e a técnica de análise de conteúdo serviu de base para auxiliar na interpretação dos dados. Foi possível constatar que a construção de carreira gerencial é distinta num contexto sócio-histórico-cultural, similar nas características globais do desenvolvimento profissional de um gerente, tais como habilidades técnicas e interpessoais e que há colisão de gerações de gerentes nas organizações, sendo estas interessadas em desenvolver e manter concomitantemente as duas gerações em convívio e produção, visando treinamentos de aproximação de técnicas e vivências.
\end{abstract}

Palavras-chave: Construção de carreira; Gerentes; Recrutamento.

Abstract: The aim of this article is to explore aspects of career management in the current context of private companies, in the view of senior recruiters high hierarchical level and newly hired junior. The construction of the individual's career is highlighted and becomes the permanent focus to monitor the status quo and future projections forward positioning of the organizations that are always looking for the best way to retain their talent. The developed research is qualitative and data generation was through interviews and content analysis technique was the basis for aid in the interpretation of the data. It was found that the construction of managerial career is distinct from a socio-historical-cultural context similar in overall characteristics of the professional development of a manager, such as technical and interpersonal skills and that there is a clash of generations of managers in organizations, which are interested to develop and maintain concurrently two generations living and production to training approximation techniques and experiences.

Keywords: Career Construction; managers; Recruitment.

Data de submissão: 27/02/2017 Data de aceite: 05/04/2018 Data de publicação:

1 Doutoranda pela Universidade Federal de Lavras - UFLA no Departamento de Administração e Economia (DAE) com

Ênfase na Linha 2: Organizações, Gestão e Sociedade com formação completa prevista para dezembro/2018.

2 Doutorado em Administração pela Universidade Federal de Minas Gerais - UFMG (2006).

$3 \mathrm{PhD}$ in Management - Organizational Studies - by the Graduate Program in Management (Federal University of Lavras/UFLA) (2012-2016). 


\section{INTRODUÇÃO}

Nas atuais estruturas organizacionais e mercadológicas brasileiras, a internacionalização, globalização e inovação estão presentes tanto nos processos produtivos quanto gerenciais, tornando inevitáveis as discussões, reestruturações e redefinições das relações com o trabalho. Esta imprevisibilidade contemporânea acompanha o percurso de boa parte dos profissionais. Sendo assim, a construção da carreira do indivíduo ganha destaque e passa a ser o foco permanente ao monitorar o status quo e as projeções futuras frente ao posicionamento das organizações que buscam sempre a melhor maneira de reter seus talentos. Neste ambiente de competitividade, instabilidade econômica e relacional, destacam-se o grau de empregabilidade caracterizado pelas condições de inserção e permanência no mercado de trabalho privado dos profissionais em cargos gerenciais, que estão inclusos na lógica produtiva e estratégica da organização.

Para os profissionais em cargos gerenciais, com autonomia para elaboração e execução do processo de recrutamento e seleção, questões como a centralidade, representatividade, influência do trabalho e da carreira permitem possibilidades de como trabalhar e, portanto, de como assumir o trabalho cotidianamente. Os recrutadores são pivôs da gestão empresarial, isso porque eles formam o elo entre as exigências e perspectivas organizacionais, e as expectativas dos egressos, buscando uma convergência e equilíbrio organizacional entre os objetivos dos empregadores e os interesses dos candidatos (VASCONCELOS et al 2016; ALVES e ALMEIDA, 2009)

Tanto no processo de recrutamento e seleção, quanto na ambientação de um novo profissional recém-formado à realidade organizacional, nota-se que há relação simbiótica entre o recrutador e o contratado. Nesta relação é importante destacar que a representação do trabalho e a construção da carreira são diferenciadas pelas diferentes gerações, considerando os contextos históricos e as próprias vivências profissionais e acadêmicas, condizentes com a geração na qual cada um se enquadra. Destaca-se que, mais relevante que as nomenclaturas sobre as gerações, é a compreensão de conduta global de quem se enquadra nelas por período histórico-sócio-cultural (VASCONCELOS et al 2016; ALVES e ALMEIDA, 2009; LIMA et al, 2012).

A geração dos recrutadores seniores de alto escalão das empresas privadas é caracterizada pela formação baseada na experiência profissional consolidada. Até o final do século XX, o início da construção de carreira se dava ainda na adolescência. Ingressava-se no mercado de trabalho informal, polia-se o ofício e se iniciava o galgar lento de posições hierárquicas. Dessa forma, a carreira gerencial iniciava-se em posicionamento nos diversos cargos hierárquicos menores, a permanência na empresa era visada tanto pelos colaboradores quanto pela organização, e a especialização do trabalho ocorria espontaneamente alinhando a experiência prévia e a educação posterior (TANURE, NETO e ANDRADE, 2006; LIMA et al, 2012).

Já a nova geração de gerentes brasileiros do século XXI, tem a construção de carreira marcada pela formação generalista e infidelidade à empresa. Nesta nova realidade, os comportamentos mercadológicos e sociais começam a exigir o diploma universitário como requisito básico para o ingresso no mercado de trabalho, uma realidade que ainda persiste e se encontra em curso: os candidatos primeiro se qualificam e depois procuram colocação de acordo com a formação acadêmica (ALVES e ALMEIDA, 2009).

Entre o ingresso na universidade e a busca pela colocação profissional, pouco há de congruência na realidade regional e compatibilidade com a formação e oportunidades 
universitárias, fazendo com que os atuais recém-formados tenham alta capacitação generalista e pouca experiência profissional e focal. Todas essas características condizentes com um período histórico-sócio-cultural em que o acesso à diversidade na formação superior são amplos (BENDASSOLI, 2009).

\subsection{Problema de pesquisa e objetivos}

Essa divergência de formação e vivência entre as diferentes gerações dos recrutadores e dos recém-formados caracteriza sua relação, na qual há conflitos entre duas condutas pessoais e profissionais distintas, que mesmo assim, devem convergir em prol do bom funcionamento organizacional.

Com base nesta discussão pergunta-se: quais são as características das relações interpessoais (comportamento) e interacionais, se a ascensão em cargos gerenciais é distinta entre as diferentes gerações dos ocupantes destes cargos?

O objetivo principal deste artigo é explorar aspectos da carreira gerencial no contexto atual de empresas privadas, no ponto de vista de recrutadores seniores de alto escalão hierárquico. Os objetivos específicos são: primeiro, avaliar as divergências na construção de carreira gerencial dos recrutadores entrevistados com relação aos recém-formados; segundo, analisar as similaridades na construção de carreira gerencial dos recrutadores com relação aos recém-formados; e terceiro, averiguar o papel das organizações em mediar o relacionamento entre recrutadores e novos gerentes.

Justifica-se este artigo pela sua contribuição na expansão do campo teórico e da prática acerca da realidade contemporânea do ingresso e permanência no mercado de trabalho, além de traçar, mesmo que de forma introdutória, as características geracionais que compelem à conduta organizacional e gerencial. Destaca-se que este trabalho busca uma contribuição para o estado da arte discutindo através da bibliografia e das análises observações aquém da teoria de competências, sendo assim, não há escopo, neste recorte utilizado neste artigo para estudo de competências, mas sim, foco na preparação e vivências.

Após esta introdução do tema, o artigo está estruturado em seções que contemplam a fundamentação teórica, a discussão sobre a construção de carreira gerencial em detrimento das condições histórico-sócio-culturais brasileiras, que arraigaram a formação pessoal e profissional dos recrutadores e dos novos gerentes. Logo após, segue a descrição metodológica, que guiou a construção empírica deste artigo, finalizando com as análises e considerações finais.

\section{FUNDAMENTAÇÃO TEÓRICA}

2.1. Discussões Introdutórias acerca da Historicidade e Construção de Carreira: o encontro entre gerentes seniores e juniores no atual mundo corporativo

A palavra 'carreira' origina-se do latim via carreria, que significa passagem rápida, ágil. Carreira consiste no conjunto de atributos profissionais muito além do conceito de competência, que distinguem a trajetória de um indivíduo em ascensão social e profissional. Ou seja, carreira significa destacar-se dentro da profissão escolhida, através do exercício distinto do trabalho com o objetivo de crescimento e destaque profissional (AMARAL et al 2012). 
As pesquisas sobre carreira tratam da simbiose que ocorre entre a escolha profissional e os interesses pessoais. Sendo assim, não há como definir se o trabalho é central ou não na vida do indivíduo, de acordo com a compreensão de carreira. Há sim vivência, que torna o exercício da profissão mais oportuno ou não em determinadas situações. Fato central é o desejo de crescimento dentro da profissão e o reconhecimento social, havendo correlação entre trabalho, profissão e profissional (KILIMNIK, DIAS e JAMIL, 2012).

De acordo com Faro et al. (2010), há duas linhas principais de análise da construção de carreira: ancoragem e mito proteu (ou autodirigida). A ancoragem é o modelo clássico. Entende-se que a carreira é fundamentada nas bases de influência social. Mesmo que o indivíduo tome a decisão profissional por livre arbítrio, sempre haverá impulsionamento dos graus de formação de opinião e influência, como a âncora familiar e a âncora social. Como caso clássico no Brasil, encontramos nas carreiras de profissionais liberais os egressos dos cursos de Direito e Medicina que sempre apresentaram a influência e o grau de reconhecimento social, tendo inclusive intitulados tais profissionais como doutores.

Uma prática ainda presente nos dias de hoje e ilustrando bem a ancoragem como um modelo clássico. A construção de carreira clássica no Brasil do século XX ainda está muito presente na realidade brasileira por influência histórica, política e social. Geralmente, as carreiras eram definidas pelas grandes famílias patriarcais que constituíam grande prole e já definindo previamente quem seria na família, o médico, o advogado e o padre. A carreira eclesiástica era muito valorizada pela grande força e influência da Igreja Católica no processo político e de formação da sociedade brasileira (AMARAL et al 2012).

Atualmente, com a reduzida influência da Igreja nesse processo de construção de carreira, o padre já não é mais uma das principais opções. O desenvolvimento e industrialização do país, antes agrário, passaram a valorizar, também, outra carreira já no início do século XX, a do engenheiro, que dependendo da localização geográfica e condições sociais da região, consideram o engenheiro, também um doutor. Ainda, de acordo com Motta et al (2009), o engenheiro ainda percebe o seu lugar social na sociedade brasileira, reproduzida no discurso da mídia quanto a sua posição privilegiada na hierarquia das corporações.

A avaliação de carreira pelo processo de ancoragem permite designar scores (notas em porcentagem) para o grau de influência de cada uma das âncoras, sendo assim uma avaliação objetiva dos tipos de influência que o indivíduo recebe no seu processo decisório profissional. A objetividade da análise de carreira pelo processo de ancoragem limita a avaliação do contexto global e diminui a importância dos acasos no processo de tomada de decisão profissional (LUPPE e ANGELO, 2010).

Já a autogestão ou mito proteu, consiste na responsabilização total do sujeito pela tomada de decisão dos processos profissionais de sua carreira. Essa corrente surgiu nos últimos dez anos, quando as pesquisas sobre colocação no mercado de trabalho e construção de carreira começaram a inclinar-se numa diversidade ampla sobre os direcionamentos dados ao trabalho a cada indivíduo. Nesse cenário, onde o mercado prezava cada vez mais a diversidade e as universidades preparavam candidatos ressaltando seus valores diferenciais, a autogestão da carreira se tornou o foco das atenções (FONTENELLE, 2006).

Bem como a ancoragem, o mito proteu também tem suas características e limitações. Perceber que o profissional tem capacidade e desejo de mover sua carreira é necessário para avaliá-lo e ainda, considerar que, mesmo com influências externas, o tipo de subjetivação dada a cada influência e experiência são únicas (MOURA e SOARES, 2009). 
Apesar da avaliação por ancoragem e por autogestão terem evoluído em momentos distintos da história da construção de carreira, são complementares entre si. Mesmo que se responsabilize o profissional pela construção de sua carreira (mito proteu) suas decisões e escolhas jamais serão completamente livres de influência (âncoras de carreira). Isso porque a regulação de convívio social e a satisfação pessoal estão tão ligadas aos desejos e expectativas das pessoas que convivem com o profissional (família, pares) quanto com o profissional (LIMA et al, 2012; VASCONCELOS et al, 2016).

Toda e qualquer alternativa de escolha profissional traz as incertezas da tomada de decisão. Se antes a estratificação não permitia a execução de novos ofícios, hoje a escolha faz com que um leque de novas oportunidades se abra, mas com isso, a responsabilidade de que uma escolha tomada erroneamente pode prejudicar não só o trabalhador, mas também, toda uma estrutura micro social que se mobiliza para concretizar a construção de carreira deste indivíduo. Se até o final do século XX a escolha profissional era estratificada, o acesso a ensino formal era limitado e posterior à experiência e ingresso no mercado de trabalho, no início do século XXI, a variedade de cursos na formação superior é emergente e sedutora, a capacitação é prevalente à experiência e anterior ao ingresso no mercado de trabalho (NORONHA et al. 2006).

Esses elementos históricos, que compõem uma realidade distinta sociocultural das gerações de profissionais, fazem com que a identificação, a representação e as formas de conduta perante o trabalho, o emprego e o cargo sejam distintos. A gerência dessa colisão se torna evidente nos contextos organizacionais, principalmente em cargos de maior expressão social, grau de responsabilidade hierárquica.

Neste contexto destaca-se que não só a construção da carreira, mas o imaginário social dessa construção é relevante para o trabalhador, ou seja, não basta alcançar os objetivos propostos da carreira, mas também, como a carreira é representada. Ressalta-se, neste âmbito, a carreira gerencial, que independente das gerações, representa a reafirmação social e valorização do esforço investido, independente do modelo de regência da construção de carreira. A carreira gerencial é vista como a reafirmação e comprovação de que todo o processo de escolha posterior foi executado com maestria (BENDASSOLI, 2009).

Tem-se em vista que a carreira gerencial nas empresas privadas, pensando no atual contexto brasileiro, emerge para a colisão entre a experiência dos gerentes seniores e a expectativa de inovação nos gerentes juniores. Com formações pessoais e profissionais distintas é quase impossível ignorar que a relação que se estabelece, tanto na competitividade no mercado de trabalho quanto no estilo de gestão e construção de carreira são codependentes. As parcerias estabelecidas entre estes atores são a fim de suprir suas necessidades mutuamente, entretanto, existe um gap ocasionado pelas expectativas e perspectivas sociais, bem como sua identidade na sociedade e na organização (GARCIAARACIL, 2008).

Com base na revisão de literatura, é possível dizer que a mistura intrínseca da carreira gerencial e do estilo de construção de gestão de carreira (ancoragem e mito proteu), são similares para as diferentes gerações de gestores. Isto porque, historicamente, não há como conceder prevalência de um tipo de construção de carreira ou de outro, porque os estilos de ancoragem e mito proteu são codependentes, bem como a representatividade pessoal e social da carreira gerencial. O que, possivelmente, diferencia e promove a colisão de gerações gerenciais é a conduta perante os estilos de influência e autonomia, que historicamente, estão relacionados ao enfrentamento pessoal e profissional, refletindo na 
atualidade organizacional nas formas de performances, expectativas e perspectivas perante as diferentes gerações de gerentes.

FIGURA 1: Demonstração da Construção de Carreira dos Gerentes no Contexto Organizacional e Histórico

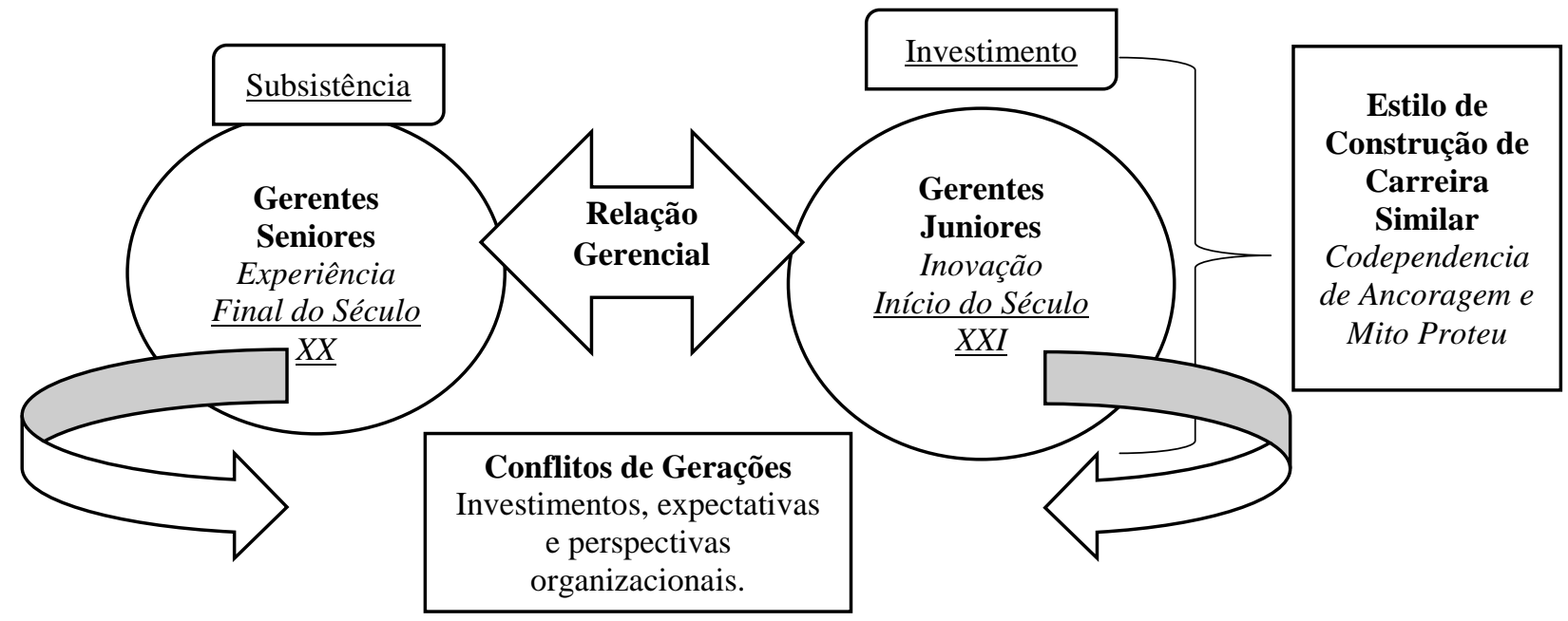

FONTE: Elaborado pelos Autores

Na figura 1, demonstra-se que a base de expectativa organizacional gerentes juniores e seniores é distinta (experiência e inovação), devido à oferta de expertise diferenciada de cada um, que é derivada da historicidade do enfrentamento dos elementos de representatividade do trabalho. A ideologia da carreira gerencial é idêntica no imaginário social e os estilos de construção de carreira são coexistentes, sendo impossível tanger prevalência de um ou outro nas diferentes gerações de gerentes.

Sendo assim, demonstra-se que o esforço para que seja produtiva a colisão de gerações é dependente das estruturas organizacionais, que permitem que a relação gerencial seja intrínseca entre gerentes seniores e juniores, promovendo o melhor aproveitamento de ambos. Apesar de serem evidentes as diferenças entre as gerações de gerentes, é necessário compreender o papel de cada um e os recursos das organizações para melhor aproveitamento destes.

A seguir, apresenta-se a descrição metodológica desta pesquisa que visa compreender tais relações.

\section{METODOLOGIA}

\subsection{Natureza da pesquisa}

Esta pesquisa possui natureza qualitativa, pois não visa compilação analítica numérica, mas sim, avaliação contextual (RAMPAZZO, 2005). Partindo da natureza qualitativa, o método de investigação é definido como exploratório que visa a um levantamento de amostra intencional em um universo específico. As pesquisas sobre trajetórias profissionais 
com a abordagem qualitativa, de acordo com Vasconcelos et al. (2016) tem apresentado resultados mais robustos, principalmente, quando relacionadas ao uso de entrevistas.

\subsection{Descrição da coleta de dados}

A coleta de dados foi realizada por meio de entrevistas em profundidade, permitindo tanto direcionamento na arguição quanto a livre interferência do pesquisador em aspectos específicos de cada entrevistado respondente (RAMPAZZO, 2005). Previamente à entrevista em profundidade, cada respondente assinou o Termo de Consentimento Livre e Esclarecido (TCLE) permitindo a manutenção do sigilo de identidade e também a possibilidade de suspender e encerrar a entrevista a qualquer momento.

\subsection{Descrição dos respondentes da pesquisa}

A amostra da pesquisa é intencional porque há direcionamento específico da caracterização e seleção dos participantes, com descrição de fatores de inclusão e exclusão para os respondentes (RAMPAZZO, 2005).

Foram selecionados gerentes que exercem atividades de recrutamento e seleção, atendendo a três critérios de inclusão: primeiro, exercer função de recrutamento e seleção nas empresas em que atualmente trabalham; segundo, atuar em empresa com estrutura física estabelecida; e terceiro, atuar numa empresa que contrate profissionais recémformados para cargos gerenciais. Os trabalhos de carreira tendo a escolha desta categoria profissional são incipientes, pois de acordo com o levantamento de Vasconcelos et al. (2016) esta profissão não é a mais visada pelos pesquisadores, que tem focado mais outras ocupações como as de professores, bancários, vendedores, administradores e profissionais de tecnologia de informação.

Para maior variedade da amostra, foram selecionados seis gerentes que atuam em empresas de três portes distintos caracterizados pelo portal do Banco Nacional do Desenvolvimento Econômico e Social (BNDES, 2014) que classifica as empresas pela receita operacional bruta anual. A caracterização do BNDES incluiu microempresas e pequenas empresas, mas, como para tais as contratações de recém-formados para cargos de gerência são mais escassas, optou-se por entrevistar profissionais de recrutamento e seleção que atuem em: média empresa, média-grande empresa e grande empresa localizadas em Minas Gerais. Os entrevistados selecionados possuíam formações acadêmicas diversas, a fim de se buscar maior diversidade nos discursos.

TABELA 1: Descrição Detalhada dos Gerentes (G) Respondentes da Pesquisa

\begin{tabular}{|c|c|}
\hline Classificação das Empresas (BNDES, 2014) & Formação Acadêmica/Categoria da Empresa \\
\hline \multirow{2}{*}{$\begin{array}{l}\text { Empresa de Médio Porte: receita maior que } \mathrm{R} \$ 16 \\
\text { milhões e menor ou igual a } \mathrm{R} \$ 90 \text { milhões. }\end{array}$} & G1.Psicologia/ Empresa Regional \\
\hline & G2.Administrador /Instituição \\
\hline \multirow{2}{*}{$\begin{array}{l}\text { Empresa de Médio-Grande Porte: receita maior que } \\
\mathrm{R} \$ 90 \text { milhões e menor ou igual a } R \$ 300 \text { milhões. }\end{array}$} & G3. Contabilidade / Empresa Regional \\
\hline & G4. Ciências Naturais / Empresa Nacional \\
\hline \multirow{2}{*}{$\begin{array}{l}\text { Empresa de Grande Porte: receita maior que } \mathrm{R} \$ 300 \\
\text { milhões. }\end{array}$} & G5. Administração / Multinacional \\
\hline & G6. Psicologia / Multinacional \\
\hline
\end{tabular}

FONTE: Dados da Pesquisa

3.4 Técnica de análise dos dados 
Optou-se pela técnica de análise de conteúdo, passando por três momentos: o primeiro é a descrição analítica dos dados coletados por fragmentação e por análise conjunta; o segundo momento é a sustentação da análise descritiva por meio do referencial teórico; e o terceiro momento é o desenvolvimento de categorias de análise que agrupassem as análises e permitissem a corroboração das perguntas levantadas na pesquisa (BARDIN, 2009).

A análise de conteúdo consiste na análise fragmentada e conjunta das parcelas das entrevistas que atendam ao objetivo geral e aos objetivos específicos da pesquisa, caracterizando-se como análise de conteúdo por grade fixa, ou seja, as categorias de análise surgem mediante busca pela resposta dos objetivos pré-determinados na pesquisa, antes da coleta dos dados.

TABELA 2: Descrição das Categorias de Análise de Dados por Análise de Conteúdo

\begin{tabular}{|l|l|}
\hline \multicolumn{1}{|c|}{ Objetivos Específicos } & \multicolumn{1}{|c|}{ Categorias de Análises Fixas (Títulos) } \\
\hline $\begin{array}{l}\text { 1.Avaliar as divergências na construção de carreira } \\
\text { gerencial dos recrutadores com relação aos recém- } \\
\text { formados. }\end{array}$ & $\begin{array}{l}4.1 \text { "Experiência versus Inovação: A Relação Pródiga } \\
\text { Entre os Gerentes Seniores e Juniores." }\end{array}$ \\
\hline $\begin{array}{l}\text { 2.Analisar as similaridades na construção de carreira } \\
\text { gerencial dos recrutadores com relação aos recém- } \\
\text { formados. }\end{array}$ & $\begin{array}{l}4.2 \text { "Experiência com Inovação: A Relação Simbiótica } \\
\text { Entre os Gerentes Seniores e Juniores." }\end{array}$ \\
\hline $\begin{array}{l}\text { 3.Averiguar o papel das organizações em mediar a a } \\
\text { carreira dos recrutadores e dos novos gerentes. }\end{array}$ & $\begin{array}{l}4.3 \text { "A Tendência das Organizações: Busca Pelo } \\
\text { Equilíbrio Vivencial e Gerencial das Diferentes } \\
\text { Gerações de Gerentes." }\end{array}$ \\
\hline
\end{tabular}

FONTE: Dados da Pesquisa

Antes de serem analisadas, as entrevistas foram gravadas eletronicamente e transcritas ipsis litteris em todo o seu conteúdo. A apresentação dos resultados da pesquisa se dá por meio das categorias analíticas previamente selecionadas.

Após coleta e tratamento dos dados, seguem abaixo as análises.

\section{ANÁLISE DOS RESULTADOS}

4.1 Experiência versus Inovação: a relação pródiga entre os gerentes seniores e juniores

O primeiro objetivo específico deste artigo é avaliar as divergências na construção de carreira gerencial dos recrutadores com relação aos recém-formados. Questionando os recrutadores, destacam-se três momentos da construção de carreira que, de acordo com os respondentes, são distintos entre eles e os novos gerentes: o ingresso, a ascensão e a permanência na empresa e no mercado de trabalho.

Para os respondentes, há três divergências no momento do ingresso na empresa e no mercado de trabalho: os recrutadores seniores ingressavam por meio de indicação, tinham baixa exigência sob as condições de trabalho e alto limiar de dedicação ao trabalho e à empresa. Já os recém-formados que ocupam os novos cargos gerenciais ingressam por meio de um processo seletivo extenso, tem altas expectativas sobre o trabalho e a empresa e baixo limiar de negociação perante estas expectativas, focando num desempenho pessoal e não coletivo. Segundo Lima et al. (2012) esta nova geração apresenta valores diferentes dos seniores porque considera mais o prazer como sentimento incluído na escolha profissional e 
seu foco é mais na carreira do que na empresa, pois prioriza os próprios interesses e no seu grau de empregabilidade.

A indicação e o processo seletivo formal tem o mesmo peso em importância para a empresa, mas a indicação por vezes é mais rápida, efetiva e eficaz. O vínculo entre indicador e indicado é uma relação intimista, que permite a vinculação do ato da contratação à gratidão do candidato à empresa e ao recrutador, e responsabilização do recrutador pelo desempenho do mesmo (COSTA, PINTO e OLIVEIRA, 2011).

Normalmente, ele (o processo seletivo) acaba sendo por indicação. Necessita disso inclusive, o recrutamento e seleção precisa, necessita disso também. Porque é um nível maior e vai de repente gerenciar, por exemplo, um grupo de 100 pessoas (...) Você precisa de referência desse profissional! (G3)

Na verdade o sistema de indicação, não é um 'tabuzão', ninguém gosta de falar, mas a gente sabe que existe porque funciona. (G6)

Tanto a indicação quanto o processo seletivo são utilizados, e eficientes na captação de novos colaboradores. Mas com os encargos específicos de uma posição gerencial, com exceção das vagas de trainee, a indicação tem mais eficiência na triagem de habilidades gerenciais e compatibilidade com o ambiente organizacional. O processo seletivo por vezes só é aplicado com o interesse de divulgação da empresa e reafirmação de sua competitividade no mercado de trabalho, ou seja, a indicação ainda é utilizada e promove resultados, mas a forma como é vista pelos recém-formados e pelos recrutadores é diferenciada.

Além disso, o processo seletivo é comumente aplicado atualmente porque a diversidade dos candidatos é alta e o acesso de informações que permitam "maquiar" as fases do recrutamento e seleção são intangíveis, fazendo com que a indicação seja uma alternativa e ao mesmo tempo, fazendo com que os processos seletivos assumam características pirotécnicas (BEYDA e CASADO, 2007).

Os recrutadores entrevistados ressaltam que durante e após o processo seletivo e/ou indicação, nota-se que a capacidade de negociação e flexibilidade para ser disponível às exigências da empresa está escassa entre os recém-formados. Se os gerentes seniores tinham disponibilidade e interesse de se doar às demandas e estruturas organizacionais, agora de acordo com os recrutadores, os recém-formados têm uma visão prévia e inegociável do que é a vaga de emprego, dificultando a captação de candidatos e hostilizando a relação inicial entre quem já é colaborador da empresa e quem deve ingressar.

Eles (recém-formados) acham assim: eu já estou formado, eu sei muito da minha área, olham, por exemplo, o nível salarial de uma pessoa que já está ali, e quer isso, as condições de que vem há vários anos está na profissão (G3).

Eu acho que hoje assim, o acesso, às empresas, por exemplo, hoje você tem a própria internet um modo geral, tem vagas de emprego no Pará, no Maranhão, todos os lugares do Brasil, não é igual antes que você ficava restrito no seu meio. Então hoje (...) o cara que tá desempregado, ele não tem que desesperar mais como antigamente, então ele ficou mais exigente, mesmo desempregado, ele vive um monte de coisa, quer um salário mínimo $x$, ele quer às vezes um carro pra trabalhar, enfim (G6). 
Destaca-se também a divergência da realidade sócio histórico e econômica entre os gerentes seniores e juniores. As oportunidades eram limitadas pela falta de acesso à informação e baixa capacitação formal, hoje as oportunidades de capacitação e acesso à informação permitem ampla competição e uma construção de carreira gerada por oportunidades e não por necessidades, apesar de serem primordiais na subsistência humana (LEMOS, DUBEUX e PINTO, 2009; VASCONCELOS et al, 2016). Cabe ainda destacar, segundo Motta et al (2009) que os profissionais seniores ainda vivenciaram parte do período militar repressivo e por uma posterior abertura política, mas com recessão econômica, insegurança financeira.

O nível de exigência dos recém-formados tem crescido porque há autoconhecimento de sua capacitação, permitindo negociação dos termos de sua contratação. Além disso, as redes de network e de informação do recém-formado permitem que vagas de seu interesse cheguem ao seu conhecimento, além da disposição de atuar fora do eixo sul-sudeste. Isto faz com que os novos gerentes negociem suas condições antes da contratação e com que esta negociação se estenda nas suas expectativas de crescimento. Ou seja, se os gerentes seniores tinham fidelidade às empresas por medo de um mercado escasso aliado à internalização espontânea das estruturas da organização, os gerentes juniores, ao questionar esta realidade são fiéis à sua carreira e não à empresa, que se torna um alicerce e não a fundamentação em suas carreiras (VASCONCELOS et al, 2016; LIMA et al, 2012).

Ao falar da ascensão da carreira, nota-se três discrepâncias entre as duas gerações, sendo: a construção da educação (formal e tácita), a transposição de cargos hierárquicos, e relação com a empresa e com a rotina de trabalho.

Para os recrutadores, a dificuldade no trabalho era maior no início de carreira do que é hoje para os recém-formados. Isto ocorria pela falta de recursos de treinamento disponíveis à empresa, as chances de ingressar num cargo de gerência eram baixas porque o início em qualquer empresa era pragmaticamente em cargos operacionais, e as chances e diversidade de formação acadêmica eram reduzidas (a descrição da formação acadêmica dos recrutadores - vide item metodologia de pesquisa - comprova tal evento).

Se, para os recrutadores, assumir o cargo de gestão era o reconhecimento após investimento na empresa, para os recém-formados é o reconhecimento do tempo investido na formação acadêmica. Têm-se então os recrutadores que adquiriam experiência e posteriormente se capacitavam de acordo com as exigências do trabalho já assumido, e de outro lado os recém-formados que fazem o caminho inverso.

Eu era recém-formado, mas já tinha nove anos de hospital. (G2)

Eu acho que tem mais oportunidades, na minha época era muito engessado. Você era médico, engenheiro, professor, assim as profissões eram rígidas, você formava para ser aquilo e pronto. Hoje você faz medicina e dá aula, a amplitude é enorme. Foi uma adequação, eu via necessidade da empresa ia lá e aprendia (..) (G4)

Os recrutadores, em sua época, buscavam estabilidade, por isso dedicavam-se à empresa, para depois dar mais a si e se especializar. Hoje os recém-formados buscam crescer, construir suas carreiras, independentemente da empresa, a instabilidade faz parte deste processo. Isto caracteriza tanto as escolhas de capacitação formal que eram por necessidade e hoje caracterizam-se por oportunidade, mas também a construção do conhecimento tácito, o que é aprendido na convivência e vivência (SALA e TREVISAN, 2009).

A educação formal, posterior às exigências do trabalho, permitiu aos recrutadores adaptação assertiva às exigências do cargo e às da organização, então sua relação com o 
trabalho se caracterizava pela fidelidade e permanência na mesma organização. Assim, a conduta dos recrutadores na construção de carreira gerencial era marcada pelo galgar lento de posições com formação direcionada e com processos bem definidos e extensos ao longo do tempo. Tudo isto fazia com que o crescimento técnico fosse acompanhado da capacitação interpessoal.

Já os gerentes juniores têm sua construção de carreira marcada pela formação acadêmica posterior à experimentação do/no mercado, ocasionando lenta adaptabilidade ao contexto organizacional, em contramão às altas exigências e expectativas que têm. Portanto, de acordo com a visão dos recrutadores, a conduta dos recém-formados é marcada pelo desequilíbrio entre conhecimento técnico e interpessoal e pela instabilidade do desejo de permanência, fatores decorrentes de uma formação generalista. Além de um sentimento para que tudo aconteça rapidamente, o que gera maior tensão quando se deseja alcançar logo o posto almejado, produzindo a inquietação que o induz a buscar outras oportunidades.

Eles (recém-formados) não tem paciência. Ás vezes sabem muito mais que a gente mas a falta de paciência é fatal. A gente contrata, depois de algumas semanas eles (recém-formados) já questionam porque não são promovidos. Eles confundem reconhecimento de obrigação (G1).

(...) É muito comum em RH a gente falar em perfil de uma outra pessoa x y z. A primeira coisa que eles vão correr atrás do cara é experiência dele profissional. (...) (...)mas se o cara não tiver uma 'experienciazinha' ali, ele vai passar aperto, entendeu? Com exceção do programa de trainee e essas coisa assim, sabe. (G6)

Retomando que para cada geração há divergência do contexto sócio-históricocultural, é necessário destacar que há eventos que promovem a construção da carreira gerencial que são intangíveis pelos profissionais. São características de espontaneidade do mercado e do comportamento das organizações e a junção destes fenômenos é que caracteriza a reação das duas gerações de gerentes (BEYDA e CASADO, 2007).

Pode-se destacar, como exemplo desta mutualidade comportamental e relacional, as características diferenciadas da permanência na empresa. Na geração dos recrutadores, o peso da responsabilidade familiar, a impossibilidade de vislumbrar um cenário econômico próximo e a representação social atrelada ao nome da empresa traçavam um perfil de permanência nas empresas por necessidade e conduta tradicionalista. Na geração dos recém-formados a instabilidade econômica traça um perfil de construção de carreira autocentrada, mais dependente da visibilidade do próprio nome do que da empresa. Além disso, os gerentes juniores são marcados por uma conduta inovadora e de aversão à rotina, então a mudança é sinônimo de desafio, se tornando atrativo.

É salutar destacar que, mesmo com as diferenças caracterizadas pela geração atrelada a um contexto sócio-histórico-cultural, há similaridades na conduta e construção de carreira gerencial de ambos os gerentes.

4.2 Experiências com Inovação: a relação simbiótica entre as duas gerações

O segundo objetivo específico deste artigo é analisar as similaridades na construção de carreira gerencial dos recrutadores com relação aos recém-formados. Ao questionar os recrutadores há destaque para duas evidências, correlacionadas ao comportamento interpessoal que, segundo eles, são similares na construção de carreira gerencial de ambos, 
sendo estas evidências: interesse em lidar com pessoas (comunicar-se e estabelecer network), capacidade de improvisação e agilidade na tomada de decisão).

Para os entrevistados, o desenvolvimento das habilidades interpessoais permite que o gerente se coloque melhor no seu ambiente social e, portanto, desperte maior interesse das empresas por ele. Apesar de ser importante para o processo seletivo e para a contratação, as habilidades interpessoais como comunicação e adaptabilidade, não são ensinadas nem pelas universidades e nem pelas empresas, são estruturadas internamente pela construção do conhecimento tácito, pelo vivencial.

Eu acho que independente de ser graduado ou técnico, o relacionamento interpessoal é obrigatório, para desempenho e sobrevivência, na vida e nas corporações (G1).

A relação interpessoal hoje é fundamental em todos os níveis dentro da empresa, independente se ele vai exercer um cargo de liderança de gestão, independente disso, a relação interpessoal hoje, pode-se dizer que é uma necessidade de sobrevivência desse profissional dentro do mercado. Ele pode ser um expert técnico, ter uma graduação exemplar, mas se não tem uma relação interpessoal dentro da organização, ele não consegue sobreviver. Não só dentro da organização, dentro do mercado de trabalho. Então essa variável, relação interpessoal, ela se faz necessária pra que a pessoa cresça evidentemente que tem outras variáveis, mas essa é muito necessária, a ter essa relação (G5).

A cobrança das empresas e dos recrutadores com os relacionamentos interpessoais é embasada na maior dificuldade em desenvolvê-los. Para as empresas e recrutadores, o relacionamento interpessoal vem da adaptabilidade de cada indivíduo, e só a vivência desenvolve esse quesito tão visado (CAVAZOTTE, LEMOS e VIANA, 2012; ALVES e ALMEIDA, 2009).

As características comportamentais de um candidato são desenvolvidas considerando todo o seu contexto ao longo de sua trajetória de vida pessoal, acadêmica e profissional e não apenas das atividades acadêmicas durante a graduação que têm um papel preponderante para desenvolver suas características técnicas que de fato importam para o exercício da profissão (ALVES e ALMEIDA, 2009).

De acordo com os recrutadores, nota-se a capacidade de gerenciar de um recémformado a partir da sua comunicação e das relações que ele estabelece dentro do trabalho, ao mesmo tempo, mantendo a network pré-estabelecida antes de conquistar a vaga de emprego. A forma de comunicar é única do cargo, da empresa e da atividade, então uso de jargões e vocabulário técnico, fazem parte do processo de ambientação dos novos gerentes, e reciclagem dos antigos gerentes. Mesmo que haja divergências, a comunicação constantemente é um fator de igualdade, porque independentemente da construção de carreira dos gerentes, a forma de se fazer entendido e entender a organização é idêntica, promovendo assim, convivência próxima das gerações.

Os recrutadores relatam que esta manutenção das relações traz benefícios tanto para os novos gerentes, que aceitam melhor as críticas, trazendo resultados mais rápidos para a organização, quanto para eles próprios (recrutadores) que renovam seu repertório comportamental e relacional, aliando o tradicionalismo da conduta interna à organização, com a busca pela inovação criativa, característica forte na nova geração de gerentes.

$\mathrm{O}$ entrincheiramento entre as condutas e comportamentos das diferentes gerações de gerentes permite com que a organização tome benefício tanto da inovação competitiva que é necessária para atrair clientes e se manter em destaque, quanto no tradicionalismo 
dos processos que por vezes, precisam permanecer pragmáticos para garantir melhor aproveitamento e maior lucro (BASTOS e BORGES-ANDRADE, 2002; ALVES e ALMEIDA, 2009).

Eu acho assim, primeiro foi o que eu te disse é gostar do que faz, gostar de pessoas, você tem que gostar da companhia do outro, de dividir (G4).

Os recrutadores relatam que a necessidade de saber e gostar de lidar com pessoas é comum a qualquer gestor. De acordo com os entrevistados, o comportamento humano nas organizações, que rege todos os produtos e processos, é imprevisível, mas demanda controle. Portanto, ao aprender, saber e gostar de lidar com pessoas, as imprevisibilidades passam a fazer parte do trabalho. Desta forma, a improvisação pela adaptabilidade é necessária e característica de qualquer gerente. Todos os gerentes, no cotidiano, buscam alcance das metas produtivas e ao mesmo tempo, processos de conduta específicos a serem seguidos. É uma linha tênue entre a improvisação e burlar o sistema, e como gerente converge, por exemplo, o comportamento de seus supervisionados, esta é uma habilidade primordial.

Nota-se, com as análises até então, que o perfil dos gerentes converge na questão comportamental, mas diverge na vivencial e educacional. Então é necessário compreender como as organizações contemporâneas buscam sincronizar para melhor absorção das funções, as capacitações de duas gerações distintas, mas necessárias nas estruturas organizacionais.

4.3 A Tendência das Organizações: busca pelo equilíbrio vivencial e gerencial de seniores e juniores

O terceiro objetivo específico deste artigo é averiguar o papel das organizações em mediar a carreira dos recrutadores e dos novos gerentes. Para tanto, os recrutadores relatam que o caminho que as empresas têm tomado é no investimento de treinamento individual. Independentemente da modalidade (mentoring, counseling, coaching), há um novo gerente recém-contratado que é guiado por um gerente sênior, já estabilizado na organização contratante.

Estes treinamentos fazem com que a ambientação do novo gerente seja congruente com a realidade do seu trabalho, precavendo-se de turnover e pouca produtividade, e há baixo custo de investimento na realização do treinamento (BASTOS e BORGES-ANDRADE, 2002).

Ao mesmo tempo, o sênior é reciclado ao estar em contato constantemente com um colega recém-formado, e é motivado, porque há possibilidade de nova ascensão de cargo, uma vez que há outra pessoa treinada e seus conhecimentos são diretamente passados a outro indivíduo (tanto com a capacitação técnica de exigência do cargo quanto pela forma de fazer as funções que só o antigo funcionário sabe).

Tem que ter um pouco de paciência, eu acho que você tem que entrar na empresa e aprender, porque você 'tá' formando agora nunca trabalhou, você não sabe nem o que aquela empresa. Eu acho que tem que ir devagar um pouco. Igual aqui, eu fiquei sete anos, depois eu já passei pra diretoria, então espera um pouco que eu acho que oportunidade, se você for bom, for interessado e mostrar pra que você veio acho que com pouco tempo você consegue subir (G2). 
A rotatividade da mão de obra se torna alvo devida à falta de carreira e sucessões, a falta de benefícios, enfim (G5).

Percebe-se que as empresas desejam e desenvolvem táticas para manter seus novos gerentes. Por isso, muitas organizações adotam políticas agressivas de bônus e outras formas de remuneração variável. Ao mesmo tempo, os recrutadores participam deste processo, socializando sua experiência para os recém-formados, buscando principalmente a paciência destes para que se vislumbre, em longo prazo, o compromisso do novato com o futuro da organização e os benefícios de permanecer na empresa contratante. Quando os novos gerentes vêem imediatamente que há um plano de carreira para eles, desde os primeiros dias de trabalho, apesar dos percalços dentro do exercício da profissão, o desejo de permanência na empresa é renovado. Além disso, a valorização dos conhecimentos do sênior faz com que ele reacenda seu interesse pelo trabalho e pela empresa.

\begin{abstract}
Os problemas estão mudando, hoje tá tendo mais opções pra você contratar, existe um leque melhor de você contratar sim, é, um problema de hoje em relação ao passado é (..) a fidelidade a empresa. (...) Antigamente a pessoa tinha fidelidade com a empresa, hoje não, hoje o mercado é mais promissor, roda mais, os profissionais ficam na empresa, é, se tiver ascensão, se tiver uma, os benefícios já pré-fixado e também a sua escalada de crescimento, correta e pré-fixada. Caso não tenha o profissional fica pouco tempo na empresa (G5).
\end{abstract}

Os investimentos em treinamento, uma vez realizados trazem reconhecimento e novas oportunidades para os gerentes. Uma vez investido no funcionário, o interesse da empresa aumenta na mão de obra que está sendo qualificada de acordo com seus moldes e com o seu investimento financeiro, o desligamento deste funcionário se torna uma realidade possivelmente mais distante (DIAS-COSTA e CALADO-DIAS, 2011).

Ele (recém-formado) vem pra aprender, então tem empresa que não tem essa paciência, disponibilidade de pessoal pra poder, 'num' tem uma estrutura adequada pra ensinar.(...) Então é importante também, assim pra empresas ter esses órgãos do governo que fazem essa parte, de habilitar os aprendizes(G3)

As empresas, quando não tem suporte interno para realizar o programa de treinamento in company, há parcerias que são estabelecidas em prol do recém-formado e da empresa contratante. As empresas tem interesse de manter seus novos e antigos talentos, $\mathrm{e}$ precisam por questões inclusive financeiras. Com candidatos preparados, os processos seletivos têm ficado cada vez mais caros e não é de interesse da maior parte das empresas ter cargos táticos com rotatividade.

\title{
5 CONCLUSÃO
}

O objetivo principal deste artigo foi explorar aspectos da carreira gerencial no contexto atual de empresas privadas, no ponto de vista de recrutadores seniores de alto escalão hierárquico. Após o levantamento de literatura pertinente ao tema e análise do conteúdo empírico, constatou-se que a construção de carreira gerencial é distinta num contexto sóciohistórico-cultural, similar nas características globais do desenvolvimento profissional de um gerente (habilidades técnicas e interpessoais) e que há colisão de gerações de gerentes nas organizações, sendo estas interessadas em desenvolver e manter concomitantemente as 
duas gerações em convívio e produção, visando treinamentos de aproximação de técnicas e vivências.

Nota-se, com as análises, que as diferenças de geração que fazem a construção de carreira de um recém-formado e que fizeram a de um recrutador estão relacionadas ao ingresso no mercado de trabalho e representação do trabalho. Além da conduta pessoal que visa no primeiro crescimento acelerado na hierarquia e reconhecimento imediato, e no segundo que visa estabilidade, fidelidade e crescimento hierárquico dependente de tempo e investimento posterior à contratação.

É necessário destacar que as formas de retenção de mão de obra gerencial das organizações, também tem influência nesta construção de carreira. Na geração dos seniores, a capacitação formal, além de ser congruente com a experiência dentro da empresa, era ofertada pela mesma, que dava além de subsídios financeiros, disponibilidade de tempo e garantia de permanência e crescimento. Na geração dos juniores, a contratação em cargos gerenciais só ocorre com a formação universitária já realizada, poucas (ou nenhuma) são as empresas que cedem subsídios para a capacitação formal e com frequência contrata-se para alto escalão (como, por exemplo, no processo de trainee) recém-formado sem experiência gerencial, permitindo ambientação de acordo com os moldes da empresa.

Nota-se também que há interesse das empresas em alinhar a experiência com o fugaz na nova geração, bem como interesse da coexistência das duas gerações de gerentes e se relacionarem nas organizações, tendo em vista que há constatação de similaridades bem como as diferenciações.

Sugere-se para estudos futuros a realização desta pesquisa com outros entrevistados de outros grupos profissionais e empresariais em outras regiões do país. Também de pesquisas que visem compreender o alinhamento prático dos treinamentos personalizados das organizações com relação à sua eficácia de aprendizagem, tanto quanto sua eficácia na manutenção relacional de antigos e novos gerentes.

\section{REFERÊNCIAS}

AMARAL et al.I.G. Carreira, Mercado de Trabalho e as Lições de "Donana" no Processo de Ensino Aprendizagem e Pesquisa em Administração. Revista Eletrônica de Ciência

Administrativa (RECADM). vol.11. №1. Paraná. 2012.

ALVES, .P.S.; ALMEIDA, A.M.F. O Valor do Diploma nas Práticas de Recrutamento de Grandes Empresas. Revista Cadernos de Pesquisa. Vol.39 no138. set/dez. 2009.

Banco Nacional do Desenvolvimento acesso http://www.bndes.gov.br/.

BARDIN, L. Análise de Conteúdo. Lisboa, Portugal, Edições 70, LDA, 2009.

BASTOS, A.V.B.; BORGES-ANDRADE, J.E. Comprometimento com o Trabalho: Padrões em Diferentes Contextos Organizacionais. RAE, vol.42, nำ2, 2002.

BENDASSOLI, P.F. Recomposição da Relação Sujeito Trabalho nos Modelos Emergentes de Carreira. RAE, vol.49, n느, 2009. 
BEYDA,T.T.; CASADO,R.U. Dilemas na Ruptura com o Mundo Corporativo. XXXI Encontro da ANPAD. 22 a 26 de setembro de 2007. Rio de Janeiro/RJ.

CAVAZOTTE, F.S.C.N.; LEMOS, A.H.C.; VIANA, M.D.A. Novas Gerações no Mercado de Trabalho: expectativas renovadas ou antigos ideais? Cadernos EBAPE.BR, vol.10, n1, 2012.

COSTA,F.J.; PINTO,F.R.; OLIVEIRA,L.G.L. A Área de Recursos Humanos e o Interesse Profissional dos Estudantes de Administração. Revista Pretexto. vol.12,n. 3. Belo Horizonte/MG. 2011.

DIAS-COSTA,M.A.G.; CALADO-DIAS,S.M.R. Adequações de Modelos Internacionais de Mentoria e de Liderança a Empresas Brasileiras: Investigação em um Call Center. XXXV Encontro da ANPAD. 4 a 7 de setembro de 2011. Rio de Janeiro/RJ.

FARO, E.S.C.; AMORIM, M.C.S.; TREVISAN, L.; JUNQUEIRA, L.A.P. Âncoras de Carreira e Transformações do Modelo de Administração: estudo de caso do tribunal de Contas da união (TCU). Cadernos EBAPE.BR. vol.8, nำ4, 2010.

FONTENELLE, I.A. "Eu Proteu”: A Auto Gestão da Carreira Entre Fatos e Mitos. XXIX Encontro da ANPAD. 2006.

GARCIA-ARACIL, A. College Major and the Gender Earnings Gap: A Multi-Country Examination of Postgraduate Labour Market Outcomes. Res. High Education. vol.49, no1, 2008.

KILIMNIK,Z.M.; DIAS,S.M.O.; JAMIL.G.L. Fatores de Pressão no Trabalho e Comprometimento com a Carreira: um Estudo com Profissionais de Tecnologia da Informação. Revista Eletrônica de Sistemas de Informação. vol.11, n. 2. 2012.

LEMOS, A.H.C.; DUBEUX,B.J.C.; PINTO,M.C.S. Educação, Empregabilidade e Mobilidade Social: Convergências e Divergências. Cadernos EBAPE.BR. vol.7, no2, 2009.

LIMA, G.S.; NETO, A. C.; TANURE, B. Executivos jovens e seniores no topo da carreira: conflitos e complementariedades. REAd | Porto Alegre - v. $71-n^{\circ} 1-$ janeiro/abril, 2012.

LUPPE,M.R.; ANGELO,C.F. As Decisões de Consumo e a Heurística da Ancoragem: Uma Análise de Racionalidade do Processo de Escolha. Revista de Administração do Mackenzie (RAM). v.11, n.6. São Paulo. 2010.

MOURA.M.A.; SOARES,F. A Sustentabilidade da Carreira dos Profissionais do Século XXI: Reflexões Sobre as Competências Baseadas no Comportamento de Entrega e o Mito Proteu. Revista Gestão e Tecnologia. vol.9, n. 2. 2009.

MOTTA, P. C.; GOMES, M. Z.; VALENTE, P. Venderam Meu Futuro: Crise e a Nova Geração. Revista Pensamento Contemporâneo em Administração, v. 3, n. 2, 2009. 
NORONHA, A.P.P. et al. Análise de Teses e Dissertações em Orientação Profissional. Revista Brasileira de Orientação Profissional. v.7. n.2. 2006.

RAMPAZZO, L. Metodologia Científica: para alunos dos cursos de graduação e pósgraduação. São Paulo: Edições Loyola, Ed. 3, 2005.

SALA,O.T.M.; TREVISAN,L.M. Competência e Carreira Profissional: Tendências de um Objeto de Estudo Sob as Abordagens Multidisciplinares. Revista de Gestão organizacional (RGO). v.2, n. 2. 2009.

TANURE, B.; NETO, A.C.; ANDRADE, J.O. A Super Executiva às Voltas com a Carreira, Relógio Biológico, Maternidade, Amores e Preconceitos. XXX Encontro da ANPAD. 23 a 27 de setembro de 2006. Salvador/Bahia.

VASCONCELOS, V.C.; BORGES-ANDRADE, J.E.; PORTO, J. B.; FONSECA, A.M.O.; Carreira nas organizações. Revisão da produção brasileira no âmbito do micromportamento organizacional. Rev. Psicol. Organ. Trab., jan-mar, 2016, v.16, n.1. 